\title{
Cardiac Tamponade in Infant First Manifestation of Primary Hypothyroidism: A Rare Occurrence
}

\author{
Anirban Chatterjee ${ }^{1}$, Suman Sarkar ${ }^{2}$ \\ ${ }^{1}$ Assistant Professor, Institute of Post Graduate Medical Education and Research, Kolkata, West Bengal, India \\ ${ }^{2}$ Assistant Professor, Institute of Post Graduate Medical Education and Research, Kolkata, West Bengal, India
}

\begin{abstract}
We are reporting an infant presented with cardiac tamponade which is the first presentation of previously asymptomatic primary hypothyroidism. After literature search, we found our patient is the first infant from India and the youngest reported as of now, was managed by Pericardiocentesis and thyroxin replacement. In addition, microcytic anemia because of hypothyroidism complicated the case. Hypothyroid-pericardial effusion infant with anemia have never been reported earlier.
\end{abstract}

Keywords: Cardiac tamponade, infant, Primary Hypothyroidism, Anemia, Pericardiocentesis

\section{Introduction}

A pericardial effusion and cardiac tamponade is mostly caused by infections ${ }^{1}$ in Pediatric age group. That is an extremely rare complication of hypothyroidism in children ${ }^{2}$. And pericardial effusion may be associated in $50-73 \%^{3}$ hypothyroid children, but none of the study reported symptomatic pericardial effusion or cardiac tamponade in infants. ${ }^{2}$ Sometimes the cardiac tamponade can be the first manifestation of hypothyroidism in Down syndrome. ${ }^{4}$

\section{Case Report}

A 10-month - female presented with cough for 10 days, sudden onset respiratory distress for one day and no history of fever. She was born of full term normal vaginal delivery. Perinatal and neonatal period was uneventful. On admission, she had moderate pallor, no cyanosis, normal temperature, respiratory rate of $56 / \mathrm{min}$, heart rate of $160 / \mathrm{min}$, blood pressure was $78 / 36 \mathrm{~mm} \mathrm{Hg}$ with feeble peripheral pulses. Dysmorphism was not found. Cardiovascular examination revealed distant, muffled heart sounds. Respiratory system was normal and no hepato-splenomegaly. No previous record of Anthropometric measurement was available except birth weight (2600gms). She weighed $8.2 \mathrm{~kg}$ (between 10thto 50thpercentiles for age), head circumference was $43.5 \mathrm{~cm}$ and length was $70 \mathrm{~cm}$ (both between 3rdto 10thpercentile for age).

A chest x-ray showed a huge cardiac silhouette (cardiothoracic ratio 0.7) and clear lung field. Electrocardiogram revealed low voltage complexes. An Echocardiography obtained shortly after admission demonstrated normal heart, a large pericardial effusion with diastolic collapse of the anterior right ventricular free wall, which was suggestive of cardiac tamponade and it was treated by pericardiocentesis. Analysis of pericardial fluid showed pale straw color, glucose 72mg /dl (normal 106-159 $\mathrm{mg} / \mathrm{dl}$ ), total protein $4.7 \mathrm{gm} / \mathrm{dl}$ (normal 2.8-3.8 mg/dl ), cholesterol $186 \mathrm{mg} \mathrm{dl}($ normal $29-58 \mathrm{mg} / \mathrm{dl}$ ) cell count 480 , neutrophil $30 \%$, macrophage $70 \%$, plenty of $\mathrm{RBC}$. Gramstain and Ziehl-Neelsen were negative. Culture of percardial fluid showed no growth of organism. BACTEC culture of blood was negative. Hematology tests revealed hemoglobin level of $6.9 \mathrm{gm} / \mathrm{dl}$, total leukocyte count of $7,500 / \mathrm{cmm}$ (37\% neutrophils and 63\% lymphocytes) and platelets of 1.7 lakhs / cmm. Peripheral smear showed microcytic anemia. Total iron binding capacity and Serum Ferritin were within normal limit. Renal and liver functions were normal.

Considering large pericardial effusion, length closed to $3 \mathrm{rd}$ percentile and anemia, patient was advised for thyroid test. Her thyroid profile was total Triiodothyronine (T3): 0.68 $\mathrm{ng} / \mathrm{ml}$ (reference range $0.8-2 \mathrm{ng} / \mathrm{ml}$ ], total thyroxin: (T4) $1.4 \mu \mathrm{g} / \mathrm{dL}$ (reference range 4 to $12 \mu \mathrm{g} / \mathrm{dL}$ ) and thyroid stimulating hormone (TSH): $29 \mu \mathrm{IU} / \mathrm{mL}$ (reference range 0.4 to $6 \mu \mathrm{IU} / \mathrm{mL}$ ). Low T4, T3 and elevated TSH have proved of primary clinical hypothyroidism of the patient. In addition, a radiograph the lower limbs proved delayed bone age, absent tibial epiphysis.

Chromosomal analysis showed 46XX.

After 3 months of levothyroxine $(8 \mu \mathrm{g} / \mathrm{kg}$ per day) treatment, TSH was $19 \mu \mathrm{IU} / \mathrm{mL}$, Small pericardial fluid and hemoglobin level was $9.3 \mathrm{gm} / \mathrm{dl}$

\section{Discussion}

We are presenting an infant with cardiac tamponade because of previously asymptomatic primary hypothyroidism. A massive pericardial effusion and cardiac tamponade rarely described as an initial presentation due to hypothyroidism in non-syndromic children. ${ }^{2}$ This is First report from Indian non-syndromic infant and the youngest patient presented in the Emergency and saved by immediate Pericardiocentesis. Furthermore, anemia recognized complication of hypothyroidism has not been previously reported associated with hypothyroidism - pericardial effusion in children.

The effusion in hypothyroidism is caused by increased capillary permeability and an impairment of lymphatic drainage of interstitial protein ${ }^{5}$; subsequently albumin-rich fluid is accumulated into the pericardial space. The high protein content of pericardial fluid is characteristic of the effusion because of hypothyroidism. ${ }^{6}$ The cholesterol-rich

\section{Volume 4 Issue 8, August 2015}




\section{International Journal of Science and Research (IJSR) \\ ISSN (Online): 2319-7064}

Index Copernicus Value (2013): 6.14 | Impact Factor (2013): 4.438

effusion also typical that denotes impaired absorption through pericardium. In our case, high protein and cholesterol were suggestive that the effusion because of hypothyroidism.

In hypothyroidism, fluid gradually accumulates in pericardial space and allows stretching the pericardium, so it would not produce tamponade. However, the pericardial effusions of any cause in infant are more likely to develop cardiac tamponade compare to older children. ${ }^{1}$ Therefore, asymptomatic pericardial effusion in infant develops into unexpected cardiac tamponade.

Cardiac tamponade should have treated by Pericardiocentesis. Pericardiocentesis was therapeutic and diagnostic in our case to exclude other aetiology of effusion, such as infections. Some authors observed that pericardial effusion in hypothyroidism recurred after Pericardiocentesis, not regressed. ${ }^{7}$ But our patient Pericardial fluid was resolved by pericardiocentesis

In our case, microcytic anaemia with normal iron stores is consistent with anemia due to hypothyroid. Although microcytic anaemia is not found in hypothyroid adult, it can be noted in children with hypothyroidism ${ }^{9}$. Furthermore, there is a relationship between the severity hormonal defect with appearance of cardiac tamponade ${ }^{2}$ and anaemia. ${ }^{8}$

Our message: Early diagnosis of hypothyroidism by routine screening and treatment with levothyroxine could have reduced the risk of development of cardiac tamponade and unnecessary invasive procedure. In addition, hypothyroidism should have been excluded in child with pericardial effusion.

\section{References}

[1] Zreik H, Li J, Garson Jr A T. Etiology and danger of pericardial effusion in infants and children. Cardiology in the young. 1996; 06:162-5

[2] Sanda S, Newfield RS. A child with pericardial effusion and cardiac tamponade due to previously unrecognized hypothyroidism. J Natl Med Assoc. 2007; 99:1411-13

[3] Bhupathi R, Kothari SS, Gupta AK, Menon PS. Cardiac function in hypothyroid children: effect of replacement therapy. Indian Pediatr. 1999; 36:779-84

[4] Bhardwaj P, Sharma VK, Bhardwaj R. Hypothyroidism presenting as cardiac tamponade in Down syndrome. J Indian Med Assoc. 2011; 109:47-48.

[5] Parving A, Ostri B, Bretlau P, Hansen JM, Parving HH. Mechanisms of edema formation in myxedema-increased protein extravasation and relatively slow lymphatic drainage. N Engl J Med. 1979; 301:460-65

[6] Hurtado J J D, Guevara W, Ramos E, Lorenzana C, Soto S. Hypothyroidism in a five-yearold boy with rhabdomyolysis and recent history of cardiac tamponade: a case report. J Med Case Reports. 2011; 5: 515

[7] Williams LHP, Jayatunga R, Scoot O. Massive pericardial effusion in a hypothyroid child. Br Heart J. 1984; 51: 231-2

[8] Franzese A, Salerno M, Argenziano A, Buongiovanni C, Limauro R, Tenore A. Anemia in infants with congenital hypothyroidism diagnosed by neonatal screening. J Endocrinol Invest. 1996 ;19: 613-19
[9] Jen-Yih Chu, Monteleone, J A, Peden, V H, Graviss, E R.,Vernava, Anthony M. Anemia in Children and Adolescents with Hypothyroidism. Clin Pediatr. 1981;20: 696

\section{Author Profile}

Dr Anirban chaterjee MBBS, M.D. Pediatrics. He is now Assistant Professor of Pediatric Medicine and Visiting Physician in Institute of Post Graduate Medical Education and Research, Kolkata, West Bengal. He has Publication in National and Internanational Journal and keen interest in Academics

Suman Sarkar, MD Ped Med (AIIMS). He is now Assistant Professor an Faculty Incharge of Peiatric Intensive Care Unit Pediatric Medicine and Visiting Physician in Institute of Post Graduate Medical Education and Research, Kolkata, West Bengal. He has Publication in National and International Journal and keen interest in Academics 